\title{
Gênero televisivo como mediação: possibilidades metodológicas para análise cultural da televisão
}

\section{Simone Maria Rocha e Letícia Lopes da Silveira}

\section{Resumo}

Através de um breve resgate teórico do conceito de mediação segundo vertente latino-americana dos Estudos Culturais, sobretudo nas proposições de Jesús Martín-Barbero, este artigo pretende demonstrar sua importância teórico-metodológica em estudos de televisão. Ao entendermos gênero televisivo como uma mediação entre as práticas da produção, da crítica e da audiência, adotaremos os princípios da análise cultural de gênero televisivo como proposto por Jason Mittell. Nosso estudo alinha-se à perspectiva de Mittell, segundo a qual práticas culturais são constitutivas das práticas midiáticas e gênero é visto como uma importante chave de leitura quando se trata de captar os sentidos construídos e configurados pelos media. De modo a evidenciar empiricamente nossos propósitos de análise, investiremos na construção cultural do gênero televisivo minissérie.

\section{Palavras-clave}

Análise cultural. Gênero televisivo. Mediação. Minissérie.

Simone Maria Rocha I smarocha@ig.com.br Doutora em Comunicação e Cultura pela Universidade Federal do Rio de Janeiro (UFRJ). Professora do Programa de Pós-Graduação em Comunicação Social da Universidade Federal de Minas Gerais (UFMG).

Letícia Lopes da Silveira I leticia.bh@gmail.com Graduanda em Comunicação Social pela Universidade Federal de Minas Gerais (UFMG). Bolsista de Iniciação Científica.

\section{Introdução: escolhendo o percurso}

0 conceito de mediação revela uma profícua história de tradição crítica que remonta, inclusive, à dialética hegeliana com a qual, de certa forma, Raymond Williams dialogou na tentativa de problematizar a arte como ação humana criativa, numa visão contrária à tradição marxista que entendia a arte como mero reflexo a partir do modelo base/superestrutura. Desde Lukács, Goldmann, passando por Adorno percebemos a necessidade de lidar com essa ideia de intermediação entre uma base social e uma superestrutura cultural que de fato pudesse revelar como se estrutura a relação entre arte e sociedade (CEVASC0, 2001). Dentre os contemporâneos Roger Silverstone (1999, p. 33) em seu conhecido Por que estudar a mídia?, aponta a relevância de pensarmos "na mídia como um processo, um processo de mediação" entendido como a circulação de significado. Contudo, foge ao escopo deste texto inventariar o conceito de mediação sob pena de revelar-se um trabalho portentoso e incompleto. Para os propósitos deste artigo, quais sejam, argumentar 
e evidenciar o potencial teórico do conceito de mediação, interessa-nos abordar os esforços que pesquisadores latino-americanos, notadamente Jesús Martín-Barbero, têm empreendido em sua adoção para melhor compreensão das relações entre comunicação, política e cultura.

No centro do mapa das mediações comunicacionais da cultura proposto por MartínBarbero (2001) podemos visualizar a noção de gênero (GOMES, 2011). Lugar de cruzamento e de encontro entre as matrizes culturais e os formatos industriais, bem como entre lógicas de produção e competências de recepção, tal noção será explorada metodologicamente como forma de viabilizar a discussão empreendida pelo autor. Sob este aspecto, traremos a contribuição da proposta metodológica de Jason Mittell (2004) - para quem o gênero é uma categoria cultural e não textual - na medida em que nos propomos observar a constituição cultural do gênero minissérie. Empiricamente, tomamos como objeto comentários e diversas postagens em blogs e sítios na web de jornalistas, produtores e telespectadores, além do próprio material institucional da emissora Rede Globo de televisão e artigos acadêmicos. Dentre 0 infindo material possível de ser encontrado sobretudo na internet, selecionamos aqueles pertinentes à discussão empreendida nesse trabalho, ou seja, relacionadas às expectativas, percepções, conceitos e até mesmo insatisfações manifestadas em relação às minisséries produzidas pela Rede Globo nos últimos 15 anos.

\section{Encontrando pistas: mediação nos estudos latino-americanos}

0 pensamento latino-americano, do qual Martín-

Barbero faz parte, trouxe uma importante contribuição para 0 estudo das relações entre cultura e comunicação. Ainda nas décadas de 1970 e 1980 as correntes europeias muito se dedicaram à análise dos textos investindo, por exemplo, em noções advindas do estruturalismo e das leituras semióticas. Os estudos norteamericanos, por sua vez, tinham grande enfoque na Psicologia Social, com o deslocamento das análises dos textos para os usos específicos das mensagens recebidas. A contribuição latinoamericana propôs uma angulação diferente, ou seja, pensar a comunicação a partir das culturas, da vida social.

A teorização feita por Martín-Barbero apresentanos uma abordagem fundamental e complexa da noção de mediação. 0 autor não oferece 0 conceito de um modo explícito, mas, sim, nos conduz a compreendê-lo como aquilo que se refere aos "[...] lugares dos quais provém as construções que delimitam e configuram a materialidade social e a expressividade cultural da televisão" (MARTÍNBARBER0. 2001, p. 304). A cultura, a política e o campo da comunicação são as três mediações constituintes para 0 autor. Em sua concepção a dimensão política sofre uma revisão e passa a ser considerada também sob novas formas de luta e organização, como o movimento feminista que tornou público o que era privado. Nesse quadro de 
referências a política passa a ser vista e configurada, para possibilitar seu melhor entendimento, a partir da cultura e da comunicação.

É notável o investimento do autor em desvendar contextos particulares de produção de sentido que apontam não para a existência de uma cultura, mas de culturas, no plural, que dizem de grupos distintos que produzem sentidos específicos e possuem maneiras próprias de lidar com os problemas do seu cotidiano. Dessa forma, percebe-se que embora os indivíduos cristalizem e materializem os processos comunicativos, na verdade, estes não se encerram nos indivíduos, não tendo necessariamente nem um começo nem um final. ${ }^{1}$ Os sentidos a todo o momento estão sendo compartilhados, produzidos e atualizados durante os processos de interação social.

Em seu influente Dos meios às mediações, Martín-Barbero (2001, p. 278) procura entender a dinâmica complexa instaurada pelos meios de comunicação mirando seu olhar não para os seus produtos, mas antes disso, para a sua matriz primeira, a cultura, palco de uma complexa teia de relações humanas baseadas em processos eminentemente dialéticos que envolvem avanços e retrocessos, "resistências e submissões, impugnações e cumplicidades". Ao complexificar os polos da questão, o pensador espanhol procura, na verdade, enfatizar o caráter híbrido das problemáticas sociais existentes na América Latina. No entanto, é impossível negar que os meios exercem um papel importante na sociedade, movimentando as transformações sociais. Sendo assim, tais problemáticas são transpostas - não de maneira direta, mas segundo modos operatórios próprios - para o terreno ambíguo dos meios de comunicação.

Neste contexto, a visão instrumental dos meios não era capaz de compreender os processos comunicacionais. A tecnologia não pode ser reduzida a sua materialidade, pois ela envolve linguagens, ações e dinâmicas sociais, políticas e culturais. Para evidenciar e complexificar esse processo, Martín-Barbero elaborou o "mapa das medições", através do qual 0 autor pensa ser possível configurar um percurso específico de investigação da comunicação e da cultura no campo das produções midiáticas. 
Figura 1 - 0 mapa das mediações proposto por Martín-Barbero

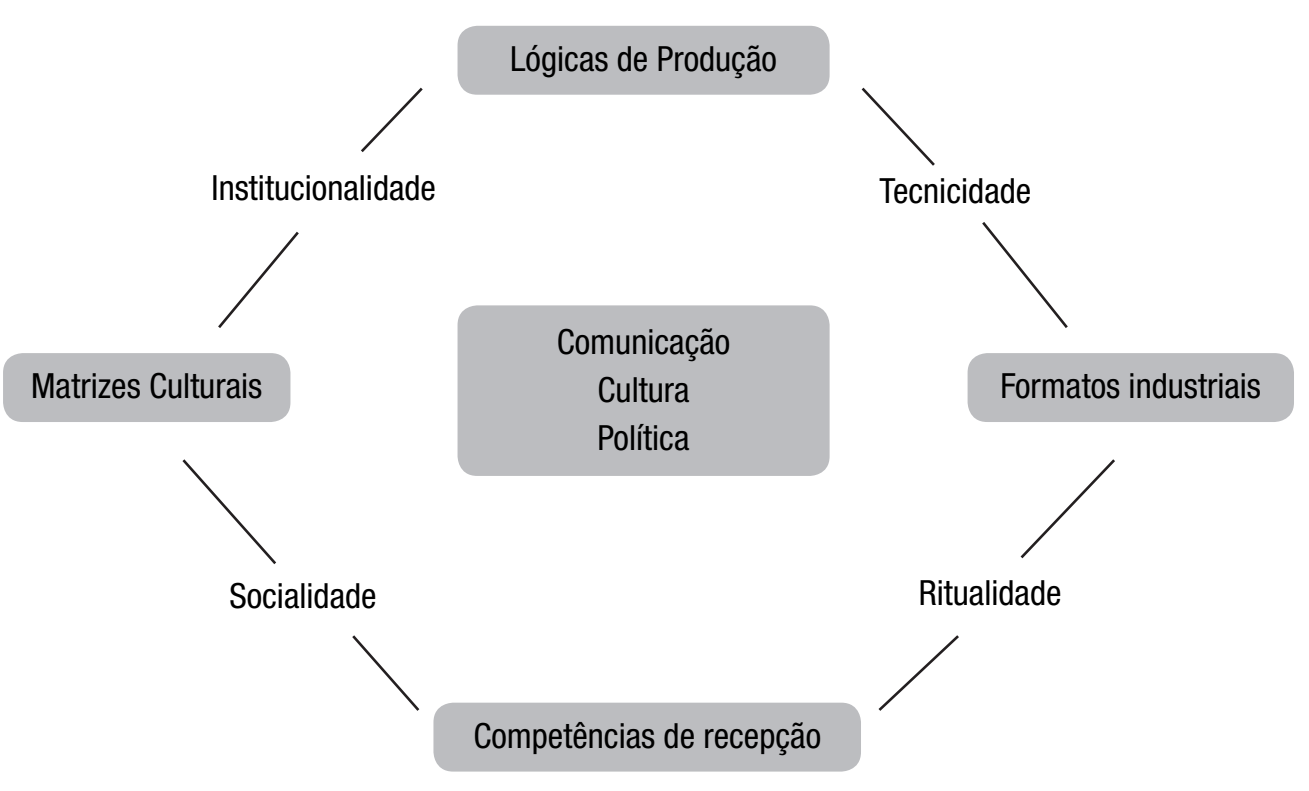

Fonte: MARTÍN-BARBER0, 2011.

Ao formular esse mapa, o autor constrói um viés que insere os media dentro de um conjunto de relações mais amplas no interior das quais eles se constituem e são socialmente apreendidos. Investigar a comunicação a partir desse enfoque envolve percebê-la enquanto processo, o que requer um olhar que se volte para as dinâmicas e os vínculos entre as lógicas de produção, as matrizes culturais, as competências de recepção e os formatos industriais.

Importante perceber que a articulação entre esses eixos se realiza e se atualiza pela e na cultura, a partir do que ele denomina mediações ou, de forma mais específica, "mediações comunicativas da cultura". ${ }^{2}$ Cada relação do mapa se dá por mediações comunicativas que são: socialidade, ritualidade, tecnicidade e institucionalidade. A tecnicidade se refere à maneira como a técnica pode ser utilizada. A institucionalidade diz respeito ao crescimento dos meios como instituições sociais e não apenas aparatos, o que nos possibilita ver as lutas travadas nas tentativas de construção de discursos institucionais. A socialidade é compreendida como o laço social que transforma as relações. A ritualidade se refere aos ritos estabelecidos na fruição dos formatos industriais que a tecnicidade possibilita. Para Ana Carolina Escosteguy (2001, p. 101):

Através das mediações é possível entender, [...] a interação entre produção e recepção ou entre as lógicas do sistema produtivo e dos 
usos, ou seja, o que se produz nos meios não responde unicamente ao sistema industrial e à lógica comercial mas, também, a demandas dos receptores, ressemantizadas pelo discurso hegemônico.

Há, assim, uma mudança de foco significativa e, através dela, torna-se possível compreender a realidade dos meios e dos produtos culturais específicos tendo em vista o conjunto de relações complexas de natureza política, cultural e comunicacional dentro das quais eles emergem e as quais suscitam. Para Escostesguy (2001, p. 101, grifos nossos):

Nos exemplos apresentados nesse livro, as mediações tanto podem ser meios - a literatura de cordel espanhola, a literatura de colportage francesa, o cinema mexicano; sujeitos - indivíduos que trabalham com a literatura de colportage; gêneros - radioteatro, folhetim, melodrama, as séries e os gêneros televisivos; e espaços - o cotidiano familiar, 0 bairro.

As proposições de Martín-Barbero, portanto, se caracterizam como um pano de fundo consistente para 0 entendimento da complexa relação entre comunicação e cultura contemporâneas e oferece pistas frutíferas para a realização de uma análise cultural com vistas a elucidar essa relação. ${ }^{3}$

\section{Esboçando direções: gêneros televisivos}

0 mapa apresentado por Martín-Barbero é muito útil aqui, pois nos ajuda a situar a noção de gênero enquanto mediação que opera entre a lógica do sistema produtivo e a lógica dos usos. Conforme este autor:

[...] No sentido em que estamos trabalhando, um gênero não é algo que ocorra no texto, mas sim pelo texto, pois é menos questão de estrutura e combinatórias do que de competência [...] A consideração dos gêneros como fato puramente 'literário' - não cultural - e, por outro lado, sua redução a receita de fabricação ou etiqueta de classificação nos têm impedido de compreender sua verdadeira função e sua pertinência metodológica: chave para análise dos textos massivos e, em especial, dos televisivos (MARTíN-BARBERO, 2001, p. 314, grifo do autor).

Ao falar sobre a televisão na América Latina, Martín-Barbero (2004, p. 317) argumenta que só é possível avaliar o peso político ou cultural da televisão em termos da "medição social que obtêm suas imagens". Essa capacidade advém justamente da expectativa que as pessoas criam em relação ao desenvolvimento tecnológico do meio, do que elas esperam, do que elas pedem a ele. Por isso, para sabermos o que a televisão faz com as pessoas temos que investigar as

Merece nota o fato de que Martín-Barbero abre constantemente seu modelo de análise a novas configurações e adaptações de modo a torná-Io mais denso epistemologicamente e capaz de dar conta dos desafios que a comunicação midiática e as transformações sociais apresentam. Tem sido assim mesmo antes de chegar a um desenho mais estruturado no prefácio à $5^{a}$. edição castelhana da obra Dos meios às mediações, intitulado Pistas para entre-ver meios e mediações (2001), passando tanto por versões anteriores da mesma quanto de outros escritos como América Latina e os anos recentes (1995), La comunicación en las transformaciones del campo cultural (1993), até chegar em Ofício de Cartógrafo (2004) e vai continuar sendo como já podemos ver em suas reflexões recentes como As formas mestiças da mídia (2009a) e Uma aventura epistemológica (2009b). 
demandas sociais e culturais que elas fazem à televisão e que se baseiam tanto nos dispositivos quanto nas modalidades de reconhecimento sociocultural que essa mídia oferece. Esse é 0 lugar dos gêneros no mapa de Martín-Barbero (2004, p. 371): "É por isso que na América Latina 0 gênero midiático que apresenta os mais densos cruzamentos das matrizes culturais populares com o formatos industriais é sem dúvida a telenovela". Ou seja, gênero é o lugar do cruzamento, do encontro, da realização: o centro do mapa. Ao abordar tal temática Itania Gomes (2011, p. 125) empreendeu esforço para ressaltar essa centralidade, uma vez que esse olhar para além do texto permite tomarmos 0 gênero como uma rica categoria cultural. Ou seja, a autora compreende 0 gênero enquanto lugar privilegiado para entrever as relações da comunicação, cultura e política: "se o gênero é uma estratégia de comunicabilidade que articula lógicas de produção com competências de recepção e matrizes culturais com formatos industriais, ele não pode estar em outro lugar".

Se, por um lado, a tecnicidade é, de algum modo, mundializada, por outro as narrativas, as ritualidades e as socialidades são diversas. E isso pode ser evidenciado nas produções do gênero que nos ajuda a ver a articulação das mediações culturais. No caso da telenovela, por exemplo, 0 autor esclarece:

Se é certo que o gênero telenovela implica rígidos estereótipos em seu esquema dramático e fortes condicionamentos em sua gramática visual [...] também o é que cada país tem feito da telenovela um particular lugar de cruzamento entre a televisão e outros campos culturais como a literatura, o cinema, o teatro (MARTÍN-BARBERO, 2004, p. 373).

Analiticamente, como pode ser observado, o percurso traçado pelo autor possui uma série de implicações que revelam a real complexidade existente por trás de tal conceito. Primeiramente deve-se notar que 0 eixo definidor do gênero (vertical) é atravessado pelas mediações constitutivas da comunicação, cultura e política, mediações essas que também fazem a ligação, no eixo horizontal, entre as matrizes culturais e os formatos industriais. Logo, conclui-se que o gênero integra numa mesma instância a vida social e a maneira como ela é registrada sob a forma de um programa televisivo. Para este autor:

0 gênero é hoje um lugar-chave da relação entre matrizes culturais e formatos industriais e comerciais. Temos vivido separando completamente estas duas coisas. Uma coisa era o estudo dos textos literários ou das matrizes culturais, e outra, o estudo dos formatos. 0 gênero é lugar de osmose, de fusão e de continuidades históricas, mas também de grandes rupturas, de grandes descontinuidades entre essas matrizes culturais, narrativas, gestuais, estenográficas, dramáticas, poéticas em geral, e os formatos comerciais, os formatos de produção industrial (MARTín-BARBERO, 1995, p. 66).

No entanto, embora 0 gênero só seja exprimível mediante uma materialidade simbólica, ele não é a materialidade simbólica, mas 0 que está 
além e aquém dela: "entre a lógica do sistema produtivo e as lógicas dos usos, medeiam os gêneros. São suas regras que configuram basicamente os formatos, e nestes se ancora 0 reconhecimento cultural dos grupos" (MARTíNBARBER0, 2001, p. 303).

Martín-Barbero (2001, p. 189) também vê $o$ gênero como uma unidade mínima de comunicação enquanto uma forma abstrata que possui necessariamente uma dimensão pragmática de reconhecimento, "falo de gênero como um lugar exterior à 'obra', a partir de onde 0 sentido da narrativa é produzido e consumido, ou seja, lido e compreendido". Por isso 0 gênero está presente nos processos de socialização humana que se desenrola a partir do reconhecimento de formas comunicativas a partir da cultura. É justamente este terreno comum que possibilita que tanto a esfera da produção quanto a da recepção se reconheçam e dialoguem, pois nas últimas décadas, talvez, a principal característica do fluxo televisivo seja, como afirma Ana Maria Balogh (2002, p. 94) "uma bricolagem de gêneros e subgêneros". Afinal, a equipe de profissionais que é responsável pela produção dos programas televisivos está mergulhada nos valores existentes e partilhados na cultura - 0 que é, inclusive, condição de possibilidade dos próprios produtos midiáticos.
Nesse sentido, olhar para a rede proposta por Martín-Barbero ajuda-nos a compreender de maneira mais efetiva a produção dos gêneros. Este autor cita P. Fabri a quem aponta como um autor que procurou compreender a especificidade cultural do massivo que assim argumenta,

$$
\begin{aligned}
& 0 \text { gênero é justamente a unidade mínima do } \\
& \text { conteúdo da comunicação de massa (pelo } \\
& \text { menos no nível da ficção, mas não apenas) } \\
& \text { e que a demanda de mercados por parte do } \\
& \text { público (e do meio) aos produtos se faz no nível } \\
& \text { do gênero. Para os investigadores, é através da } \\
& \text { percepção do gênero que se alcança o sentido } \\
& \text { latente dos textos dos mass media (FABRI, } \\
& 1973 \text { apud MARTíN-BARBER0, 2001, p. 310). }
\end{aligned}
$$

Ainda para Martín-Barbero (2001, p. 310-311, grifos nossos) assim como no cinema no qual as pessoas fazem as escolhas do que ver a partir de determinadas expectativas,

$$
\begin{aligned}
& \text { A dinâmica cultural da televisão atua pelos } \\
& \text { seus gêneros; que ativam a competência } \\
& \text { cultural e a seu modo dão conta das diferenças } \\
& \text { sociais que a atravessam. Os gêneros, que } \\
& \text { articulam narrativamente as serialidades, cons- } \\
& \text { tituem uma mediação fundamental entre as } \\
& \text { lógicas do sistema produtivo e as do sistema } \\
& \text { de consumo, entre a do formato e a dos modos } \\
& \text { de ler, dos usos. }
\end{aligned}
$$

\section{Através deste percurso teórico pudemos compreender como 0 autor elabora uma} consistente abordagem que considera os gêneros como uma importante mediação nas relações entre a comunicação e a cultura midiática. ${ }^{4}$ 
Contudo, se teoricamente tal perspectiva

evidencia a importância de pensarmos

gêneros como uma mediação nos processos

de produções midiáticas, é possível afirmar

que ela tem sido fundamentalmente adotada

nos estudos de recepção cuja preocupação

central "foi evidenciar como acontecem as

negociações e articulações dos significados

por parte dos diferentes grupos de receptores

em seus contextos culturais e sócio-históricos"

(OROFINO, 2006, p. 52). ${ }^{5}$ Além disso, conforme

Orofino (2006, p. 56, grifos da autora):

Os limites ou defasagens mais comumente apontados com relação à sua [de Jesús Martín-Barbero] abordagem teórica não dizem respeito a sua visão política, contextual e epistemológica, mas sim, às questões relacionadas à operacionalização metodológica de seus conceitos.

Nosso objetivo é propor uma análise que inclua concretamente as instâncias de produção e consumo que nos ajude a avaliar a pertinência específica desses gêneros nos processos de produção e circulação de produtos midiáticos.

Apresentaremos uma abordagem metodológica que consideramos afinada com a visada de Martín-Barbero e que nos possibilita uma análise cultural efetiva do processo de circulação, produção e consumo de um gênero televisivo e suas reverberações no tecido social.

\section{Definindo o desenho metodológico: gênero televisivo como mediação cultural ou uma análise para além do texto ${ }^{6}$}

Esboçados a partir de estudos literários e fílmicos para operar na distinção entre os principais tipos de narrativas, os gêneros televisivos tornaram-se importantes tanto para os críticos de televisão, como para os realizadores, os executivos e a audiência. Os estudos de gêneros têm se articulado com as principais tendências em estudos críticos de televisão, valendo-se de muitas teorias e abordagens. Mesmo para os telespectadores cotidianos ou aqueles mais atentos aos guias de programação da TV, a categorização dentro de gêneros tais como ficção científica, telenovela, telejornal, talk show é um componente central que nos revela 0 modo como a televisão é entendida e experimentada em diversos contextos sociohistoricos. As origens dos estudos de gênero remontam à época clássica, quando Aristóteles distinguiu entre as principais categorias dramáticas de épica, tragédia e comédia. Quando os meios de comunicação

No Brasil vários estudos (BONIN, 2002; JACKS, 1999; LOPES; BORELLI, RESENDE, 2002; RONSINI, 2004) demonstraram esse enfoque do cultural no espaço do cotidiano com significativos investimentos na pesquisa de recepção.

Essa reflexão sobre gênero televisivo como categoria cultural, conforme proposta por Jason Mittell (2004) vem sendo realizada no âmbito do Grupo de Pesquisa em Comunicação, Midia e Cultura desde 2009. Alguns artigos foram publicados (R0CHA, 2011a; ROCHA; FRANÇA, 2009) e apresentados (ROCHA, 2011b). Além disso, vários projetos de estudantes de graduação e pós-graduação têm tomado por base essa proposta, fazendo-se as adaptações necessárias aos objetos específicos de cada pesquisa. 
criaram novos modelos narrativos, as categorias de gênero tornaram-se mais específicas. Os estudos literários sofreram mudanças nesse período para considerar 0 gênero ficção como uma faceta da cultura popular e para considerar categorias como romance e mistério como principais gêneros populares. Estudiosos do cinema adotaram essa abordagem examinando a estrutura subjacente e os significados culturais de importantes gêneros de filme, como westerns e musicais. A partir do momento em que a televisão foi se desenvolvendo até se tornar o nosso meio preponderante de contar histórias, as categorias de gênero como as telenovelas, os talk shows e programas de auditório tornaram-se parte de um amplo vocabulário genérico.

Sendo assim, à medida que os estudos dos gêneros televisivos cresceram dentro dos estudos dos media, os pesquisadores (ALLEN, 1985; MARTINBARBER0, 2001; MITTELL, 2004) expandiram seus métodos e têm investigado como 0 gênero funciona como parte de um sistema de produção e de consumo televisivo, explorando como práticas que envolvem a produção televisual, a audiência e a crítica cultural, são parte do processo criativo e constitutivo de um gênero. Vistos como mediações culturais que circulam em torno e através da programação televisiva, Jason Mittell (2004) apresenta uma proposta teórico-metodológica segundo a qual os gêneros tomam por base uma abordagem influenciada pelo paradigma mais amplo da teoria pós-estruturalista a qual sugere um modo diferente de se entender a importância e a função cultural dos mesmos, o que nos leva a um caminho distinto para a pesquisa da história dos gêneros televisivos através da análise do discurso.

De acordo com esta abordagem os gêneros são construtos conceituais adotados para vincular não só os programas, mas, também, as concepções culturais que vão além deles. Essas categorias são configuradas por um conjunto de práticas culturais que se somam aos discursos genéricos, desde comentários críticos, vinhetas, sites produzidos por fãs, regulações governamentais até artigos acadêmicos. Mittell (2004) identifica três práticas discursivas em particular que são comumente usadas para constituir os gêneros televisivos: definição (por exemplo, "isto é um talk show porque um entrevistador recebe convidados num clima descontraído"), interpretação ("minha vida é uma novela!") e avaliação ("as minisséries são mais bem produzidas do que as novelas"). ${ }^{7}$

Pesquisar um gênero como mediação cultural requer a análise das várias opiniões da crítica, da audiência e de discursos institucionais sobre 0 proferem discursos de definição, interpretação e avaliação, empiricamente tal proposta se mostra de difícil execução. A primeira dificuldade diz respeito ao caráter aleatório e desordenado da aparição desses discursos e da dificuldade de organizar diferentes enunciações no interior de uma mesma categoria discursiva. No caso especifico dessa pesquisa houve, também, dificuldades de ordem material, ou seja, a profusão de discursos sobre as minisséries. Na ampla pesquisa realizada os discursos de definição eram preferencialmente proferidos por parte dos realizadores. Discursos da audiência ou da crítica eram, na maior parte das vezes, de interpretação e avaliação. 
uso de categorias genéricas, e o mapeamento das mudanças nos discursos acerca de uma categoria em particular em diferentes contextos históricos. É o que Mittell denomina "genealogia genérica", partindo da concepção de formações discursivas de M. Foucault. ${ }^{8}$ Como Mittell afirma (2004, p. 14):

[...] nós podemos olhar na direção dos modos nos quais as definições, interpretações e avaliações de gênero são parte de uma operação genérica culturalmente mais ampla. Ao invés de questões tais como 'o que uma série policial?' ou 'como nós definimos o quiz show?' nós devemos olhar para as práticas culturais de interpretação e definição de gêneros difundidas que nos levem a questões tais como 'o que os talk shows significam para uma comunidade específica?' ou 'como a definição de animação é articulada por grupos situados socialmente?'

Compreendida dessa forma, temos então a discussão de Martín-Barbero como pano de fundo na construção desse modelo de análise, na medida em que esses diversos discursos estão inseridos em tramas sociais e históricas as quais influenciam os atores sociais e seus proferimentos. Enfim, tendo essa abordagem teórico-metodológica como base de sustentação, na próxima seção analisamos a construção cultural de um gênero televisivo, o das minisséries.

\section{Empreendendo a análise: gênero televisivo como mediação cultural - consumo e produção na definição das minisséries}

Para evidenciar a proximidade da proposta metodológica de Mittell (2004) com o percurso teórico de Martín-Barbero (2001), observaremos a constituição do gênero minissérie na dramaturgia televisiva brasileira a partir de uma análise das conformações discursivas de definição, avaliação e interpretação provindas de realizadores, críticos, acadêmicos e audiência.

A definição do Dicionário Globo (2003, p. 4-5), emissora brasileira que se destaca na feitura de minisséries, caracteriza esse produto enquanto "uma ficção seriada, cujo enredo, diferente das telenovelas, está pronto antes do início da produção". Tal característica acompanha as expectativas da audiência, uma vez que é considerada fator proeminente do "alto padrão de qualidade" desse produto. Afastado de possíveis alterações devido à razões comerciais - como índices de audiência - considera-se que os realizadores adquirem maior liberdade para primar pela qualidade do programa. Essa prerrogativa pode ser observada em casos como

A concepção de formações discursivas de Foucault parece particularmente apta a análise genérica. Foucault analisa amplas formações discursivas como sexualidade, insanidade e criminalidade, argumentando que elas são sistemas de pensamento historicamente específicos, categorias conceituais que funcionam para definir experiências da cultura dentro de um amplo sistema de poder. Essas formações discursivas emergem não de uma estrutura centralizada ou de um lugar único de poder, mas são construídas da base para micro instâncias. Embora as formações discursivas sejam sempre marcadas pelas descontinuidades, elas seguem regularidades gerais, se adequando aos amplos "regimes de verdade" de uma sociedade. Finalmente, formações discursivas frequentemente parecem ser naturais ou propriedades internas dos seres, como se fossem humanas, mas são de fato culturalmente constituídas e variáveis. 
o da minissérie Amazônia (2007), em que parte de sua produção foi concomitante com a exibição na TV, gerando discussões tais como deste comentário de um telespectador postado no Orkut:

Geralmente as minisséries são escritas bem antes de irem ao ar. 0 que aconteceu com Amazônia foi parecido com o que ocorre com as novelas, a minissérie continuou sendo escrita após ir ao ar. Certamente isso prejudicou 0 planejamento do roteiro. ${ }^{9}$

Além disso, o Dicionário Globo ressalta que a minissérie é um gênero que tem privilegiado adaptações televisivas de obras literárias e homenagens a datas comemorativas e personagens brasileiros ilustres. Quanto a isso, o diretor e produtor Daniel Filho (2001, p. 63) tenta explicar as razões:

Para criar uma minissérie, o ideal é usar um bom livro, um fato histórico ou uma história oportuna sobre algo que esteja acontecendo. São as melhores maneiras; não quer dizer que não existam outras boas histórias que possam ser feitas. [...] A minissérie é o melhor veículo para adaptação de romances, no sentido de haver o mínimo de traição possível ao original. aprofundar trajetórias de personagens e de histórias longas sem deixar de lado as riquezas simbólicas. Estas, inclusive, são fonte de estudos de diversos pesquisadores brasileiros (BALOGH; DROGUETT; 2008; MUNGIOLI, 2009; PAIVA, 2007), que encontram valores culturais nessas produções baseadas em personagens, obras e ambientes que permeiam a história de nosso país. Ou seja, apontam que as minisséries contribuem com a formação do imaginário brasileiro. Como afirma Balogh (2008, p. 47), o refinamento das minisséries consegue, como nenhum outro produto televisivo, transmutar o melhor da literatura nacional e traçar perfis de heróis da "brava gente brasileira".

No entanto, é preciso considerar que essa função da minissérie só adquire sentido porque encontra respaldos na audiência e na experiência vivida dos telespectadores. Os comentários encontrados em sites e blogs sobre dramaturgia apontam como alguns telespectadores qualificam positivamente essa transposição de momentos históricos, valores culturais e personagens para as minisséries:

[...] Incrível como podemos perceber a questão histórica do machismo brasileiro, onde os homens, traíam às pampas suas esposas, e achavam que as mesmas deviam concordar com tudo aquilo! Isso mostra a força da mulher, pois quando o casal se separa, 0

Informação disponível em: <http://www.orkut.com.br/Main\#CommMsgs?cmm=6859187\&tid=2525204858233546397>. Acesso em: 04 nov. 2011.

10 As produções nacionais nem sempre dão jus ao nome, como as congêneres internacionais. Elas não possuem uma regularidade de capítulos, que variam entre quatro e sessenta episódios. 
pobre Herivelto fica apagadinho, apagadinho! (SAIBA..., 2010)

A belíssima minissérie "Amazônia" aguça a memória, o nacionalismo e, em especial, 0 ufanismo de ser acreano. É a história regional contada à feição de telenovela, trazendo cenas de intenso realismo, um pedaço da vida de tanta gente que viveu e vive, ainda, nos seringais amazônicos. [...]. (LESSA, 2011)

Porém, é curioso observar como as conformações de gênero são conflituosas e sugerem uma variação de concepções e valores culturais. Nesse caso, a proximidade com a história convoca esse tipo de incongruência, pois discursos de definição e avaliação, sobretudo de críticos especializados em TV, assim como da própria audiência, nem sempre interpretam as adaptações de nossa história como uma forma de expandir o conhecimento. Muitos acreditam que a incorporação da ficção, que reveste os fatos de dramaticidade, deturpa o que ocorreu, sendo assim, cobram dessas produções determinado padrão de legitimidade. Em algumas minisséries, por exemplo, são omitidos e modificados determinados acontecimentos apropriados em suas adaptações, de forma a dar mais movimento à trama. Recentemente essa discussão cobriu resenhas e artigos sobre a minissérie Maysa (2009):

\footnotetext{
É compreensível que na transposição de qualquer história para as telas seja permitido - e necessário - o recurso a algumas licenças poéticas, como 0 acréscimo de diálogos imaginários e situações fictícias. [...] 0 problema é quando esse tipo de artifício legítimo, no caso de personagens reais, sobrepõe-se à história
}

verdadeira, oferecendo ao telespectador uma visão distorcida dos acontecimentos, uma contrafação da biografia dos protagonistas (NETO, 2009).

Ainda mais acentuadas são as cobranças de rigor histórico das minisséries que retratam momentos da história brasileira. Durante a exibição da minissérie 0 Quinto dos Infernos (2002), historiadores se levantaram contra a forma como foi retratada a vinda da família real portuguesa para o Brasil. De maneira semelhante, muitas reclamações foram feitas devido a romantização exacerbada do líder farroupilha Bento Gonçalves, na minissérie $A$ Casa das Sete Mulheres (2003) e do político Juscelino Kubitschek, em $J K$ (2006), como demonstra o comentário abaixo:

Contudo, sem querer fazer um manifesto udenista, não há como não constatar que as licenças históricas fazem com que a minissérie enverede pelo perigoso caminho da parcialidade. 0 viés acrítico da história se reflete num Juscelino idealista, praticamente desprendido de ambições e que entra na política quase que por acaso para, só após, descobrir-se um apaixonado pela vida pública.

Preocupei-me quando li entrevista do excelente Wagner Moura afirmando que a biografia de JK foi sua principal fonte de consulta para compor o 'personagem Juscelino'. Como frisa a professora Maria Francisco Pinheiro Coelho, da UNB, em seu trabalho 'Vocação Política e Ética da Responsabilidade', '[...] escrever uma biografia é um processo de recriação do real. 0 biógrafo [...] busca a perspectiva que proporciona a melhor visão do objeto'. É justo, portanto, pensar que a narrativa de JK proporciona uma visão a se 
considerar da história. Mas seria ela a mais correta? (ONDE..., 2006)

Ao mesmo tempo, observa-se que os telespectadores têm consciência do teor ficcional das produções e de sua intenção de entreter. Pode-se observar esse relato no seguinte trecho de uma discussão entre internautas que se refere a ficcionalização da história presente na minissérie Amazônia (2007):

Eduardo, desculpe mas não concordo com a premissa de que a Globo pretende contar a história da Amazônia. Não pretende não [...]. Amazônia é assumidamente uma obra de ficção [...]. Tanto é assim que um dos protagonistas é o Galvez, personagem do mesmo Marcio Souza [...].

Concordo com o Valério num ponto: não devemos esperar que uma minissérie da Globo nos esclareça - até porque ela nunca foi vendida como documentário, mas como ficção mesmo. (Fábio Fernandes, 2007) ${ }^{11}$

Produtores também defendem essa característica da minissérie, uma produção baseada em fatos reais, mas que não se propõe fazê-lo com tanto rigor. Em uma entrevista, Maria Adelaide Amaral [2005] esclarece: "minissérie não é documentário. 0 texto é romanceado para dar um molho, mas tudo parte da realidade. Em cima do que realmente está documentado, imaginamos cenas possíveis"

Até aqui podemos perceber que essa trama de discursos que se completam e, ao mesmo tempo, se contradizem é o que molda a compreensão da minissérie e, ao mesmo tempo, nos dão a ver a relevância desse produto televisivo para o reconhecimento social de uma narrativa no interior dos media, das expectativas que cada gênero cria e dos possíveis processos de produção de sentido por parte de todos os envolvidos. Nesse sentido, os discursos acadêmicos são importantes para completá-los na medida em que nos ajudam a interpretar tais conformações da minissérie em meio ao fluxo televisivo e localizálos culturalmente.

Pensando assim, Mungioli (2009, p. 11) aponta que "[...] as minisséries brasileiras 'herdaram' em matéria de temas e de tratamento discursivo ficcional as características de um horário destinado às grandes inovações e discussões". Portanto, muitas vezes abordam temas complexos sob certo rigor de parâmetros estéticos e discursivos, reflexo percebido pela presença de autores e diretores reconhecidos e de elencos minuciosamente escolhidos e preparados nas produções desse gênero, definido com por Ana Maria Balogh (2002, p. 123) como "a crème de la crème da ficção televisual brasileira". Por essa razão perpassa as expectativas de consumo da minissérie um certo primor e esmero de produção. São empreendidos grandes investimentos financeiros, pesquisas com profissionais qualificados e equipes especializadas de toda ordem para tentar reproduzir com exatidão 
cenários, figurinos, ambientes e até mesmo toda a estrutura social das histórias que retratam cidades inteiras,costumes, linguajar, profissões etc. Então, voltando ao discursos de produtores, encontramos na seguinte fala de Daniel Filho (2001, p. 62) uma explicação para essa característica:

Quando começamos a produzir as minisséries, queríamos um aprimoramento do que conseguíamos nas novelas. De certa forma, até hoje, as minisséries provocam uma realimentação, uma releitura da novela, porque somos obrigados a usar quase a mesma estrutura dramática, mas com um outro ritmo das cenas e da própria filmagem. Há uma melhora da qualidade, as minisséries tendo um ritmo parecido com os primeiros capítulos de uma novela, com um acabamento melhor. Os atores, 0 diretor e a equipe saem do frenesi de gravar seis capítulos semanais. Sem esquecer dos autores que trabalham numa obra fechada, mais próxima de um romance, o que também facilita para eles.

Tentamos a partir do percurso empreendido até aqui demonstrar que o que especifica a minissérie enquanto gênero não são apenas as suas características textuais, mas, sim toda essa complexa construção que a insere em relações mais amplas, no medium e na sociedade em que figura. É muito mais pertinente olhar para as minisséries considerando seus significados, enquanto elementos de valor simbólico, que circulam socialmente constituindo-se e corroborando para a construção também da experiência compartilhada e das relações entre televisão e vida cultural. 0 gênero enquanto uma mediação se interpõe entre os diferentes momentos da comunicação e torna possível apreender de forma mais clara seus modos de configuração e a natureza dos laços constituídos, bem como o próprio processo de produção, consumo e circulação na cultura. Tal abordagem chama a atenção para os lugares e modos de práticas genéricas que auxiliam no entendimento de como as categorias da programação televisiva tanto definem quanto são definidas por contextos culturais e práticas discursivas.

\section{Concluindo}

Quando nos deparamos com o anúncio de uma nova minissérie vemos criadas, em crítica e público, expectativas que preparam nosso modo de apreciar essas narrativas televisivas. É nesse sentido que procuramos vincular a proposta metodológica de Mittell à noção de mediação em Martín-Barbero. A escolha pela abordagem deste autor se deu por entendermos que sua concepção de mediação nos permite enxergar o gênero enquanto tal. Por sua vez, essa concepção que entende 0 gênero como mediação nos permite articulá-la ao modo como Mittell concebe os gêneros, ou seja, como categoria cultural. Nosso investimento neste texto tentou mostrar que se teoricamente as concepções de ambos os autores se aproximam, Mittell nos oferece um caminho metodológico promissor para flagrar essa noção de gênero na prática, em uso. Certamente tendo em vista toda a carpintaria específica da produção e suas relações com o consumo não se espera de uma minissérie o mesmo que se espera de uma telenovela. Construímos uma visão de mundo 
e de país, alimentamos a memória nacional, atualizamos e descobrimos fatos que ajudaram a construir a história e a compor as identidades que compartilhamos através das narrativas trazidas nas minisséries.

\section{Referências}

ALLEN, R. Speaking of soap operas. Chapel Hill, NC: The University of North Caroline Press, 1985.

AMARAL, Maria Adelaide. 0 JK real e a lenda. Entrevistadora: Martha Mendonça. Revista Época, n. 387. [2005]. Disponível em: < http://revistaepoca.globo. com/Epoca/0,6993,

EPT1052813-1666-2,00.html> . Acesso em: 08 jul. 2011.

BALOGH, A. M.; DROGUETT, J. G. Dialogos da Antropofagia e Audiovisual. Comunicação \& Inovação, v. 9, p. $42-50,2008$.

BALOGH, A. M. 0 discurso ficcional na TV. São Paulo: EDUSP, 2002.

BONIN, J. A. Identidade étnica e telenovela.

Ciberlegenda. Niterói, n. 10, 2002. Disponível em:

$<$ http://www.uff.br/ciberlegenda/ojs/index.php/revista/ article/view/288/173>

BORELLI, S. H. S. Gêneros ficcionais: matrizes culturais no continente. In: (Org.). Gêneros

ficcionais, produção e cotidiano na cultura popular de massa. São Paulo: Intercom, 1994.

CEVASCO. M. E. Para Ler Raymond Williams. São Paulo: Paz e Terra, 2001.

ESCOSTEGUY, A. C. D. Cartografias dos estudos culturais. Belo Horizonte: Autêntica, 2001.

FILHO, Daniel. 0 circo eletrônico: fazendo TV no Brasil. Rio de Janeiro: Jorge Zahar Ed., 2001.

FEUER, J. Genre study and television. In: ALLEN,
R. Channels of discourse, reassembled. London: Routledge, 2nd edition, 1992.

FISKE, J. Television Culture. London: Routledge, 1987.

GOMES, I. M. M. Gênero televisivo como categoria cultural: um lugar no centro do mapa das mediações de Jesús Martín-Barbero. Porto Alegre: Revista Famecos, v. 18, n. 1, jan./abr. 2011. p. 111-130.

JACKS, N. Querência: cultura regional como meditação simbólica: um estudo de recepção. Porto Alegre: Ed. UFRGS, 1999.

LESSA, Luiza. A minissérie amazônia: um pedaço de cada um de nós. [2011]. Disponível em: < http:// www.gostodeler.com.br/materia/16093/a_minisserie_ amazonia

um_pedaco_de_cada_um_de_nos.html $>$.Acesso em: 09 nov. 2011.

LOPES, M. I. V. de; BORELLI, S. H. S.; RESENDE, V.

R. Vivendo com a telenovela: mediações, recepção, teleficcionalidade. São Paulo: Summus, 2002.

MARTÍN-BARBER0, J. Pistas para entre-ver meios e mediações. In: . Dos meios às mediações. 2. ed. Rio de Janeiro: Ed. UFRJ, 2011.

La comunicación en las transformaciones del campo cultural. Alteridades, México, v. 3, n. 5, p. 59-68, 1993.

América Latina e os anos recentes: 0 estudo da recepção em comunicação social. In: SOUSA, M. W. de (Org.). Sujeito, o lado oculto do receptor. São Paulo: Brasiliense, 1995. p. 39-68.

Dos meios às mediações. Rio de Janeiro: Editora UFRJ, 2001.

Ofício de Cartógrafo: travessias latinoamericanas da comunicação na cultura. São Paulo: Edições Loyola, 2004. As formas mestiças da mídia. Entrevistadora: 
Mariluce Moura. Pesquisa FAPESP Online, n. 163, p. 10-15, set. 2009a.

Uma aventura epistemológica. Entrevistadora:

Maria Immacolata Vassalo de Lopes.Matrizes, v. 2, n. 2, p. 143-162, 2009b.

MITTEL, J. Genre and television. London, New York: Routledge, 2004.

MUNGIOLI, M. C. P. Minisséries Brasileiras: um lugar de memória e de (re)escrita da nação. In: COLÓQUIO BINACIONAL BRASIL-MÉXICO DE CIÊNCIAS DA COMUNICAÇÃo, 2., 2009. São Paulo. Anais... São Paulo:, 2009. Disponível em: < http://www.espm.br/ ConhecaAESPM/Mestrado/Documents/COLOQUI0\%20 BXM/S5/maria\%20cristina\%20mungioli.pdf > . Acesso em 05 de junho de 2012.

NETO, Lira. Minissérie global simplifica e distorce a biografia de Maysa. [2009]. Disponível em: < http:// www.diretodaredacao.com/noticia/onde-a-minisserie-jkerrou >. Acesso em 05 nov. 2011.

ONDE a minissérie JK errou. 2006. Disponível em: $<$ http://www.diretodaredacao.com/noticia/onde-aminisserie-jk-errou > . Acesso em: 05 nov. 2011.

OROFINO, M.I. Mediações na produção de TV: um estudo sobre 0 Auto da Compadecida. Porto Alegre: EDIPUCRS, 2006.

DICIONÁRIO da TV Globo: programas de dramaturgia \& entretenimento. Projeto Memória das Organizações Globo. Rio de Janeiro: Jorge Zahar Ed., 2003. v. 1

ROCHA, S. M. 0 papel de críticos, realizadores e audiência na conformação de uma temática e de seu gênero: em análise o recasamento na série televisiva Tudo Novo de Novo. Contracampo, Niterói, v. 23, p. 3-18, 2011a.

ROCHA, S. M. Novas temporalidades no fluxo televisivo: apontamentos sobre a reconfiguração da experiência de assistir à televisão. In: CONFIBERCOM, 2011. São Paulo. Anais do $1^{\circ}$ Confibercom. São Paulo: USP, 2011 b.
ROCHA, S. M.; FRANÇA, R. 0. Chanchada, pornochanchada e comédia da retomada: a transformação do gênero no cinema brasileiro. Ícone, Recife, v. 11, p. 1-17, 2009.

\section{RONSINI, V. V. M. Entre a capela e a caixa de}

abelhas: identidade cultural de gringos e gaúchos.

Porto Alegre: EDIPUCRS, 2004.

SAIBA quem é quem na minissérie 'Dalva e Herivelto'. 2010. Disponível em: < http://diversao.terra.com.br/tv/ noticias/0,0I4185720-EI12993,00-Saiba + quem+e + quem + na + minisserie + Dalva +e + Herivelto.html $>$. Acesso em: 09 nov. 2011.

\section{SILVERSTONE, R. Por que estudar a mídia? São}

Paulo: Loyola, 2002.

SOBRINHO, J. B. 0. 50 Anos de TV no Brasil. Rio de Janeiro: Globo Editora, 2001. 
Television Genre as mediation: methodological possibilities for cultural analysis of televisión

\section{Abstract}

Through a brief theoretical rescue of the concept of mediation in Latin American tradition of cultural studies, especially in the proposals for Jesus Martín-Barbero, this article intends to demonstrate its theoretical and methodological importance in studies of television. We understand television genre as a mediation between the practices of production, critical and audience (Martín-Barbero, 2001). We will adopt the principles of cultural analysis of television genre as proposed by Jason Mittell (2004). Our study alligns with Mittell's perspective that cultural practices are constitutive of media practices, and genre is seen as an important key to understanding, when it comes to capturing the meanings constructed and configured by the media. In order to demonstrate empirically our purposes of analysis, we will invest in the cultural construction of television genre miniseries.

\section{Keywords}

Cultural analysis. Television genre.

Mediation. Miniseries.

\section{Género televisivo como mediación: posibilidades metodológicas para el análisis cultural de la televisión}

\section{Resumen}

A través de un rescate teórico breve del concepto de la mediación en la tradición latinoamericana de los estudios culturales, especialmente en las propuestas de Jesús Martín-Barbero, este artículo tiene la intención de demostrar su importancia teórica y metodológica en los estudios de la televisión. Entendemos género televisivo como una mediación entre las prácticas de producción, de crítica y público (Martín-Barbero, 2001). Adoptaremos los principios de análisis cultural del género televisivo como lo propone Jason Mittell (2004). Nuestro estudio comparte la perspectiva de Mittell, según la cual las prácticas culturales son parte constitutiva de las prácticas de los medios de comunicación y el género es visto como una clave importante para comprender lo que se refiere a la captura de los significados construidos y configurados por los medios de comunicación. Con el fin de demostrar empíricamente nuestros propósitos de análisis, vamos a invertir en la construcción cultural del género televisivo miniserie.

\section{Palabras-clave}

Análisis cultural. Género televisivo.

Mediación. Miniserie. 


\section{Expediente}

A revista E-Compós é a publicação científica em formato eletrônico da Associação Nacional dos Programas de Pós-Graduação em Comunicação (Compós). Lançada em 2004, tem como principal finalidade difundir a produção acadêmica de pesquisadores da área de Comunicação, inseridos em instituições do Brasil e do exterior.
E-COMPÓS I www.e-compos.org.br I E-ISSN 1808-2599

Revista da Associação Nacional dos Programas

de Pós-Graduação em Comunicação.

Brasília, v.15, n.1, jan./abr. 2012.

A identificação das edições, a partir de 2008

passa a ser volume anual com três números.

\section{CONSELHO EDITORIAL}

Afonso Albuquerque, Universidade Federal Fluminense, Brasil Alberto Carlos Augusto Klein, Universidade Estadual de Londrina, Brasil Álvaro Larangeira, Universidade Tuiuti do Paraná, Brasil Ana Carolina Damboriarena Escosteguy, Pontifícia Universidade Católica do Rio Grande do Sul, Brasil

Ana Gruszynski, Universidade Federal do Rio Grande do Sul, Brasil Ana Silvia Lopes Davi Médola, Universidade Estadual Paulista, Brasil André Luiz Martins Lemos, Universidade Federal da Bahia, Brasil Ângela Freire Prysthon, Universidade Federal de Pernambuco, Brasil Angela Cristina Salgueiro Marques, Faculdade Cásper Líbero (São Paulo), Brasil Antônio Fausto Neto, Universidade do Vale do Rio dos Sinos, Brasil Antonio Carlos Hohlfeldt, Pontifícia Universidade Católica do Rio Grande do Sul, Brasil Antonio Roberto Chiachiri Filho, Faculdade Cásper Líbero, Brasil Arthur Autran Franco de Sá Neto, Universidade Federal de São Carlos, Brasil Benjamim Picado, Universidade Federal Fluminense, Brasil César Geraldo Guimarães, Universidade Federal de Minas Gerais, Brasil Cristiane Freitas Gutfreind, Pontifícia Universidade Católica do Rio Grande do Sul, Brasil Denilson Lopes, Universidade Federal do Rio de Janeiro, Brasil Eduardo Peñuela Cañizal, Universidade Paulista, Brasil Eduardo Vicente, Universidade de São Paulo, Brasil Eneus Trindade, Universidade de São Paulo, Brasil Erick Felinto de Oliveira, Universidade do Estado do Rio de Janeiro, Brasil Florence Dravet, Universidade Católica de Brasilia, Brasil Gelson Santana, Universidade Anhembi/Morumbi, Brasil Gislene da Silva, Universidade Federal de Santa Catarina, Brasil Guillermo Orozco Gómez, Universidad de Guadalajara Gustavo Daudt Fischer, Universidade do Vale do Rio dos Sinos, Brasil Hector Ospina, Universidad de Manizales, Colômbia Herom Vargas, Universidade Municipal de São Caetano do Sul, Brasil leda Tucherman, Universidade Federal do Rio de Janeiro, Brasil Inês Vitorino, Universidade Federal do Ceará, Brasil Jnice Caiafa, Universidade Federal do Rio de Janeiro, Brasil Jay David Bolter, Georgia Institute of Technology Jeder Silveira Janotti Junior, Universidade Federal de Pernambuco, Brasil João Freire Filho, Universidade Federal do Rio de Janeiro, Brasil John DH Downing, University of Texas at Austin, Estados Unidos José Afonso da Silva Junior, Universidade Federal de Pernambuco, Brasil
José Carlos Rodrigues, Pontifícia Universidade Católica do Rio de Janeiro, Brasil José Luiz Aidar Prado, Pontifícia Universidade Católica de São Paulo, Brasil José Luiz Warren Jardim Gomes Braga, Universidade do Vale do Rio dos Sinos, Brasil Juremir Machado da Silva, Pontifícia Universidade Católica do Rio Grande do Sul, Brasil Laan Mendes Barros, Universidade Metodista de São Paulo, Brasil Lance Strate, Fordham University, USA, Estados Unidos Lorraine Leu, University of Bristol, Grã-Bretanha Lucia Leão, Pontifícia Universidade Católica de São Paulo, Brasil Malena Segura Contrera, Universidade Paulista, Brasil Márcio de Vasconcellos Serelle, Pontifícia Universidade Católica de Minas Gerais, Brasil Maria Aparecida Baccega, Universidade de São Paulo e Escola Superior de Propaganda e Marketing, Brasil Maria das Graças Pinto Coelho, Universidade Federal do Rio Grande do Norte, Brasil Maria Immacolata Vassallo de Lopes, Universidade de São Paulo, Brasil Maria Luiza Martins de Mendonça, Universidade Federal de Goiás, Brasil Mauro de Souza Ventura, Universidade Estadual Paulista, Brasil Mauro Pereira Porto, Tulane University, Estados Unidos Mirna Feitoza Pereira, Universidade Federal do Amazonas, Brasil Nilda Aparecida Jacks, Universidade Federal do Rio Grande do Sul, Brasil Paulo Roberto Gibaldi Vaz, Universidade Federal do Rio de Janeiro, Brasil Potiguara Mendes Silveira Jr, Universidade Federal de Juiz de Fora, Brasil Renato Cordeiro Gomes, Pontifícia Universidade Católica do Rio de Janeiro, Brasil Robert K Logan, University of Toronto, Canadá

Ronaldo George Helal, Universidade do Estado do Rio de Janeiro, Brasil Rose Melo Rocha, Escola Superior de Propaganda e Marketing, Brasil Rossana Reguillo, Instituto de Estudos Superiores do Ocidente, Mexico Rousiley Celi Moreira Maia, Universidade Federal de Minas Gerais, Brasil Sebastião Carlos de Morais Squirra, Universidade Metodista de São Paulo, Brasil Sebastião Guilherme Albano da Costa, Universidade Federal do Rio Grande do Norte, Brasil

Simone Maria Andrade Pereira de Sá, Universidade Federal Fluminense, Brasil Tiago Quiroga Fausto Neto, Universidade de Brasília, Brasil

Suzete Venturelli, Universidade de Brasilia, Brasil Valério Cruz Brittos, Universidade do Vale do Rio dos Sinos, Brasil Valerio Fuenzalida Fernández, Puc-Chile, Chile Veneza Mayora Ronsini, Universidade Federal de Santa Maria, Brasil Vera Regina Veiga França, Universidade Federal de Minas Gerais, Brasil

\section{COMISSÃO EDITORIAL}

Adriana Braga I Pontifícia Universidade Católica do Rio de Janeiro, Brasil

Felipe Costa Trotta I Universidade Federal Fluminense, Brasil

CONSULTORES AD HOC

Bruno Campanella, Universidade Federal Fluminense, Brasil

Gisela Grangeiro da Silva Castro, Escola Superior de Propaganda e Marketing, Brasi José Carlos Ribeiro, Universidade Federal da Bahia, Brasil

Luciana Panke, Universidade Federal do Paraná, Brasil

Micael Herschmann, Universidade Federal do Rio de Janeiro, Brasil

Tânia Márcia Cezar Hoff, Escola Superior de Propaganda e Marketing, Brasil

Virginia da Silveira Fonseca, Universidade Federal do Rio Grande do Sul, Brasil

EDIÇÃO DE TEXTO E RESUMOS I Susane Barros

SECRETÁRIA EXECUTIVA I Juliana Depiné

EDITORAÇÃo ELETRÔNICA I Roka Estúdio
COMPós I www.compos.org.br

Associação Nacional dos Programas de Pós-Graduação em Comunicação

Presidente

Julio Pinto

Pontifícia Universidade Católica de Minas Gerais, Brasil

juliopinto@pucminas.br

Vice-presidente

Itania Maria Mota Gomes

Universidade Federal da Bahia, Brasil

itania@ufba.br

Secretária-Geral

Inês Vitorino

Universidade Federal do Ceará, Brasil

inesvict@gmail.com 